\title{
Chapter 19 \\ Prospects and Pitfalls for Spectroscopic Remote Sensing of Biodiversity at the Global Scale
}

\author{
David Schimel, Philip A. Townsend, and Ryan Pavlick
}

\subsection{Introduction}

Understanding how Earth's ecosystems will respond to drivers of change requires quantifying the composition and diversity of functions (e.g., growth, nutrient uptake, decomposition) of the taxa present in those ecosystems. Biodiversity is critical to maintenance of ecosystem health, which plays a critical role in global biogeochemical cycling. In turn, human well-being is dependent on ecosystems for services ranging from food and fiber to water and air quality.

Biodiversity can change in time and space as environmental conditions change (e.g., seasonally or due to natural disturbances, human activities, or climate variability) and is changing rapidly due to climate change and human activities. Even as it does, we have remarkably little information on biodiversity worldwide, with major spatial gaps in global coverage and very limited ability to detect changes over time (Jetz et al. 2016). Ground-based repeat data are needed to track changes in biodiversity and function but are particularly sparse. Our lack of understanding of species and functional diversity in both time and space leads to great uncertainty in predicting impacts of future changes in terrestrial and aquatic coastal marine ecosystems, making this an urgent target for improved understanding.

Functional biodiversity in terrestrial and aquatic coastal marine ecosystems is controlled by environmental factors, such as soils and climate, as well as by the evolutionary history and environmental filtering of the species pool. Changes can occur at a range of temporal scales, due to both ephemeral and catastrophic disturbances as well as to long-term processes (climate change, tectonics). Even among

D. Schimel $(\bowtie) \cdot$ R. Pavlick

Jet Propulsion Laboratory, Pasadena, CA, USA

e-mail: David.Schimel@jpl.nasa.gov

P. A. Townsend

Department of Forest and Wildlife Ecology, University of Wisconsin, Madison, WI, USA

(C) The Author(s) 2020

J. Cavender-Bares et al. (eds.), Remote Sensing of Plant Biodiversity,

https://doi.org/10.1007/978-3-030-33157-3_19 
similar ecosystems (e.g., tropical rainforests in South America vs. Africa vs. SE Asia), species and functional diversity can vary widely, and differential responses of those ecosystems to change depend on their functional composition and diversity. Current ecosystem models do not have access to data representing functional diversity and need better spatially explicit and temporally resolved measurements to more accurately characterize responses to change than can be obtained from groundbased and airborne observations.

Space-based measurements add a unique dimension to biodiversity studies. No single measurement can fully characterize biodiversity, and any single measurement only captures one or a subset of the dimensions of the diversity of life on Earth. Species diversity can be captured by taxonomic identification quantified by richness and turnover, while genetic analyses can capture additional levels of variation, including within-species variation. Traits are often used to characterize diversity of function, which may or may not parallel either species or within-species diversity. Remote sensing (RS) has long been used to characterize controls or correlates of diversity such as land use, fragmentation, productivity, habitat, and habitat structure. More recently, RS has been used to measure functional diversity (Schneider et al. 2017) and spectral diversity that predicts species diversity (Gholizadeh et al. 2019) and to characterize species diversity itself (Féret and Asner 2014). RS observations are indirect in the sense that inference must be made from the interaction of electromagnetic radiation with matter, but they provide far more sampling in time and space than most in-situ techniques and so are a valuable complement for inherently variable and even ephemeral aspects of the distribution and abundance of organisms (Saatchi et al. 2015).

For decades, scientists have proposed spaceborne imaging spectrometers as a means of obtaining information about vegetation in more detail than provided by multispectral sensors (Ustin et al. 1991), but only limited actual deployments have occurred (Pearlman et al. 2003) so ecologists have had access primarily to data collected from aircraft, over relatively limited areas. While global access is valuable (i.e., the ability to sample over all or most of the world while only collecting data over particular places), global coverage has proved enormously valuable for other measurements such as greenness, and global spectroscopy will enable studies of global biogeography, biogeochemical cycles, and biodiversity. As of 2020, this capability is in planning, and global assessment of plant functional diversity is likely to become a reality by the latter part of the 2020s. This paper will serve as an introduction to the likely system so ecologists can become aware of the general characteristics of the data that are likely to become available.

In 2018, the US National Research Council released the second Decadal Survey for the Earth Sciences (National Academies of Sciences, Engineering, and Medicine 2018). This document, following the first such survey, released in 2007 (National Research Council 2007), presented a clear vision for the role of RS in addressing some of the many dimensions of biodiversity. That report notes that " $[\mathrm{k}]$ ey fluxes within ecosystems are mediated by the composition and functional traits of the organisms present. Imaging spectroscopy is a tool for determining global terrestrial and marine plant functional traits, functional types and in some cases, provides 
taxonomic composition. Traits, types, and taxonomic composition, as well as their variability and how they are changing, are poorly understood globally. Nor is there a comprehensive understanding of how they feed back to the climate system via altered biogeochemical fluxes."

The report notes that physiological, chemical and morphological traits influence the functioning of ecosystems with respect to matter and energy fluxes and emphasizes that environmental change can change the distributions of the functional characteristics of organisms, thereby potentially feeding back to the climate system and other drivers of environmental change.

The concept that the unique characteristics of organisms mediate the functioning of ecosystems, and that changes to the distribution of functional traits can feed back to the environment and even the planetary climate, leads to a key question in the report:

- What are the structures, functions, and biodiversity of Earth's ecosystems, and how and why are they changing in time and space (National Academies of Sciences, Engineering, and Medicine 2018)?

and an objective

- Quantify the distribution of the functional traits, functional types, and composition of terrestrial and shallow aquatic vegetation ... spatially and over time (National Academies 2018).

The report identifies imaging spectroscopy (IS) as "the only technology that can provide the detailed spectral data to allow identification and quantification of major biochemical and structural components of plant canopies" and calls for an instrument in orbit optimized for the retrieval of a set of plant functional traits globally and able to track their changes over time. The report identifies a set of traits for terrestrial vegetation that are priorities and that are known to be observable based on the current literature, reflecting extensive field, lab, and airborne research. These traits, shown in Table 19.1, include plant traits that are linked to growth rate, photosynthetic capacity, longevity, and the decomposition rate of nonliving plant material (Serbin and Townsend, Chap. 3).

Table 19.1 Terrestrial plant functional traits identified by the National Academies report as currently observable by remote sensing (National Academies of Sciences, Engineering, and Medicine 2018). This list includes important remotely observable plant traits, but many other traits have been identified as candidates for remote measurement

\begin{tabular}{l|l}
\hline Plant functional trait & Controls \\
\hline Chlorophyll & Photosynthesis \\
\hline Xanthophyll & Stress response of photosynthesis \\
\hline Lignin & Structure rigidity and decomposability of dead plant material \\
\hline Cellulose & Plant cell wall structure \\
\hline Leaf nitrogen content & $\begin{array}{l}\text { Photosynthesis, digestibility by herbivores, and decomposability } \\
\text { of dead plant material }\end{array}$ \\
\hline Leaf mass per area (LMA) & $\begin{array}{l}\text { Foliar morphology: ratio of foliar dry mass to leaf area } \\
\text { (reciprocal of specific leaf area, SLA) }\end{array}$ \\
\hline
\end{tabular}


The functional traits are used to estimate parameters and state variables in terrestrial ecosystem models controlling growth, turnover, and microbial respiration. As such they are key to Earth system prediction and simulation of future carbon cycling. They also define specific ecosystem characteristics. For example, chlorophyll is linked to absorption of sunlight and so affects albedo and the surface energy balance (Bonan 2016). Lignin and nitrogen content affect the palatability of forage for herbivores (Hobbs et al. 1991), thus influencing higher trophic levels, and xanthophyll indices have been proposed as leading to improved models of carbon flux (Garbulsky et al. 2010). Nitrogen additionally scales with the photosynthetic enzyme concentration of plants and therefore is a widely used indicator of photosynthetic capacity (Chapin 2003). LMA is indicative of relative investment by a plant in photosynthesis, leaf structure and/or leaf longevity and is strongly correlated with photosynthetic capacity (Poorter et al. 2009). The local diversity of plant functional traits has also been used as a predictor of plant species richness (Féret and Asner 2014) as well as for mapping functionally different plant communities (Asner et al. 2017).

The set of traits called for in the National Academies (2018) report includes plant characteristics long known to be useful for ecosystem studies (Schimel et al. 1991a), ecosystem modeling (Melillo et al. 1982), and studies of higher trophic levels (Hobbs et al. 1991). More recently, these same functional traits have been used in Earth system models (Verheijen et al. 2015) and studies of global biogeography (Butler et al. 2017; Moreno-Martínez et al. 2018). In many cases, particular species with distinct spectral characteristics can be mapped (see National Academies 2018 for a review), and phylogenetic relationships have been mapped based on spectral similarity (Cavender-Bares et al. 2016).

As a result of the studies mentioned above and many others, the National Academies (2018) report identified an imaging spectrometer with global coverage as a high priority and designated it for inclusion in NASA's next decadal program (2017-2027). This instrument, provisionally dubbed Surface Biology and Geology (SBG), is the first instrument planned for flight in the 2020s as a result of the 2018 decadal survey and could fly mid-decade. As well, the European Space Agency is proceeding with planning for the similar CHIME (Copernicus Hyperspectral Imaging Mission for the Environment) global imaging spectrometer (Rast et al. 2019).

\subsection{Characteristics and Objectives for a Global Imaging Spectrometer}

A number of IS instruments have been used for ecological studies over the years, starting with the AIS (the Airborne Imaging Spectrometer, Wessman et al. 1988) and including a number of airborne and spaceborne instruments. These instruments have all covered some part of the visible and shortwave infrared spectrum between 350 and $2500 \mathrm{~nm}$, usually with spectral resolutions of 10-40 nm. Over the evolution of this technology, the signal-to-noise performance has systematically improved, so that ever-subtler spectral features could be resolved. Many other performance char- 
acteristics have also improved with time, leading to instruments that are better and better suited for ecological applications (Asner et al. 2012).

A diversity of airborne instruments exist today. In addition, several spaceborne imaging spectrometers are likely to fly in the next decade (see below), including NASA's Earth Surface Mineral Dust Source Investigation (EMIT), aimed at studying atmospheric dust; the Hyperspectral Imager Suite (HISUI) from Japan (Ogawa et al. 2017), a general purpose instrument deployed to the International Space Station (ISS) in 2019; and EnMAP from Germany. Nevertheless, the SBG instrument is needed to meet rigorous and community-determined objectives to quantify plant functional traits globally. SBG will be aimed at studying plant functional diversity, along with aspects of geology and hydrology, and will be paired with a thermal imager designed to study hydrological and geological processes as well as thermal drivers of ecosystem processes, such as evapotranspiration. The following discussion covers only those aspects of the instrument that directly address plant functional diversity. SBG's objectives for observing plant functional diversity are summarized in Table 19.2, excerpted from the National Academies (2018) document.

The Science and Applications Traceability Matrix (SATM) for the plant functional trait designated observable of SBG (Table 19.2) allows us to see the shape of the mission likely to fly in the mid-2020s. An SATM links science of a mission to the measurements necessary for the mission's objectives, as well as providing metrics for assessment of instrument performance for those measurements. What will the data from this mission look like? The matrix defines a number of key parameters, and those parameters allow us to see the opportunities and challenges this instrument will raise, once flown.

The data, radiance measurements of reflected sunlight, should cover the spectral region from 400 to $2500 \mathrm{~nm}$, with approximately $10 \mathrm{~nm}$ spectral discretization, leading to an instrument with $>200$ spectral channels, meaning the data volume from this instrument will be very high. The information content would likewise be high, as work by Thompson et al. (2017) and Asner et al. (2012) shows that data like these collected over vegetated surfaces have as many as 30 significant principal components, meaning that pixels can be described in 30-dimensional space, while by contrast LANDSAT has 3 dimensions (Schimel et al. 2013).

The National Academies report calls for SBG's pixels to be of order 30-45 m, meaning each pixel is about $900-2000 \mathrm{~m}^{2}$, collected nominally at least every 16 , which could be halved if paired with the CHIME mission. The terrestrial Earth surface is about $2 / 3$ covered with clouds at any given time, though that varies geographically and with time of day and season, so not every acquisition succeeds in capturing the land surface. A nominal 16-day revisit means most sites will be imaged, on the average, about once a month, but in some very cloudy regions and ecosystems-for example, humid tropical ecosystems-a 16-day revisit might mean one acquisition every few years. In the National Academies (2018) report, more frequent but less spectral resolved measurements are suggested as a complement to SGB-type measurements, providing less functional information though more phenological or time series information.

Signal-to-noise ratio is one of several spectroscopic parameters that determine the information content of IS data. Gross features of plant composition emerge with 


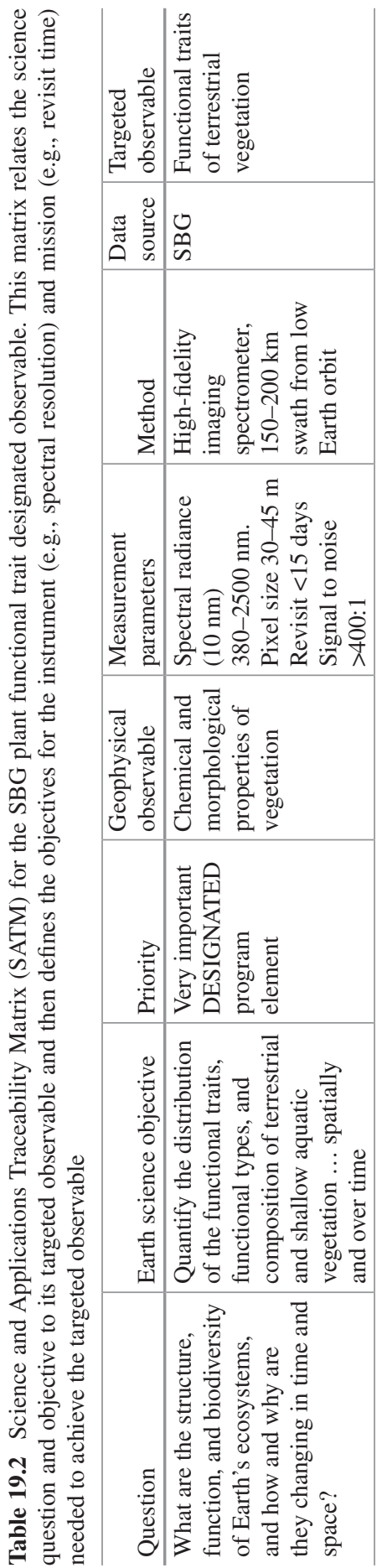


SNRs of 100-200, but modern airborne IS instruments have SNRs of $>1000: 1$, depending on the fraction of incoming sunlight reflected. The brighter the surface, the more light is reflected and the more light is incident on the instrument's detector, increasing SNR. This is also true spectrally, so even over a particular location, parts of the spectrum will have higher or lower SNR, depending on the spectral reflectance of the surface. With modern instruments (Mouroulis et al. 2011), SNR is not expected to be limiting for plant functional trait estimates.

Several other objectives for an SBG mission may be inferred from the wording of the SATM but require additional discussion to fully quantify. For example, the defining question for the plant functional trait designated observable asks why traits are changing in time and space. This implies broad coverage, ideally global, to observe spatial changes (e.g., along environmental gradients) and a long-enough time series to see at least some timescales of change.

While in many ecosystems, an SBG instrument would observe phenological change, several years or more on orbit would be required to see other types of change, such as successional change or change after disturbance. The report discusses three types of disturbance that could cause change, each with a different timescale. Wildfire causes extremely rapid change but may require decades or longer for full recovery. Pine beetle infestations, such as those have occurred in the Western United States and Canada, emerge more slowly, over several years, but may likewise trigger decades of recovery. Permafrost thaw is the slowest disturbance to emerge of the three considered; it does not lead to recovery but rather may initiate a long-term cascade of change to a new state. A global imaging spectroscopy mission would see some aspects of these disturbance processes as expressed through changing plant functional traits, but likely only a sequence of missions could see the slower aspects of recovery and change.

The formal mission study for SBG began in 2018. Some changes from the above description could occur between the National Academies (2018) definition of the observables and objectives identified for construction, so the above descriptions should be considered provisional.

\subsection{EMIT, HISUI, and EnMAP}

Several other imaging spectrometers with global access, although more limited coverage, are likely to fly before SBG. All will prove valuable in gathering imaging spectroscopy data in previously unsampled or inaccessible regions to serve as baselines for change in areas surveyed later by SBG (Schimel et al. 2013). While several other imaging spectrometers may fly, the three described below are most likely to provide data of interest to ecologists.

EMIT is a NASA Earth Venture Instrument investigation selected competitively and planned for flight on the ISS in 2021. It will be an advanced spectrometer, spanning 380-2500 nm, with $30 \mathrm{~m}$ pixels and a swath of $\sim 40 \mathrm{~km}$, aimed at studying the arid, dust source regions of the world to better understand the interaction of dust with the climate system. EMIT has a specific disciplinary focus in geology but will provide significant information about vegetation, especially in arid lands. 
HISUI is a Japanese spaceborne hyperspectral instrument being developed by the Ministry of Economy, Trade and Industry. HISUI was launched in December, 2019 onboard ISS. HISUI has 185 spectral bands from 0.4 to $2.5 \mu \mathrm{m}$ with $20 \mathrm{~m} \times 30 \mathrm{~m}$ spatial resolution with swath of $20 \mathrm{~km}$ (note the contrast in mission characteristics-SBG will have a swath of $150,200 \mathrm{~km}$ ). This narrow swath is limiting; observations have to be requested for specific targets during the planned HISUI mission lifetime of 3 years, with data availability starting in 2021.

EnMAP will orbit in a sun-synchronous orbit $653 \mathrm{~km}$ above the Earth. The satellite will be a high-resolution hyperspectral imager capable of resolving 230 spectral bands from 420 to $2450 \mathrm{~nm}$ with a ground resolution of $30 \mathrm{~m} \times 30 \mathrm{~m}$. The swath width will be $30 \mathrm{~km}$ at a maximum swath length of up to $5000 \mathrm{~km} /$ day due to data storage and downlink limits. The off-nadir $\left(+/-30^{\circ}\right)$ pointing feature enables fast target revisits of 4 days and so can be used to study phenology.

Other instruments that may be of interest include DESIS, launched in 2018 to the ISS for the German aerospace agency (with 235 bands between 400 and $1000 \mathrm{~nm}$ and $30 \mathrm{~m}$ ground resolution), and SHALOM, planned by Italy and Israel. Together, all of these instruments will begin a revolution in observation of vegetation for research and applications in agriculture and natural resources.

\subsection{Pitfalls and Opportunities in Remote Sensing of Global Plant Diversity}

Every methodology for studying biodiversity has advantages and limitations. Identifying organisms and their locations provides foundational information but only captures biological function inferentially, for example, through correlation of ranges with climate. Genomic information is extremely informative, but it can only provide inferential insight into ecological function. Functional and/or physiognomic type (e.g., graminoid, tree, evergreen, deciduous, needleleaf, broadleaf) provide broad insights into ecological niches but obscure variation of other properties within groups. Each type of observation contributes some aspect or dimension of biological diversity in ancestry, form, function, distribution, and abundance, and remote observation is no exception. Spectroscopic measurement has its own unique characteristics, which depend partly on spectral region and resolution but also on the scale and frequency of the observation. Below, we discuss three aspects of measurement and how they affect the interpretation and use of IS data.

\subsection{Vegetation Structure}

The quantitative mapping of biodiversity in ecosystems may differ by physiognomic or functional type due to (i) differences in plant size within the field of view (e.g., trees vs. grasses; see below), (ii) phenology (e.g., grasslands in which dominant species and number of species presenting to a sensor may vary across the 
growing season), and (iii) vegetation physical structure, including overall plant form and leaf shape and longevity. At the leaf level, the interaction between a ray of light and foliar tissue is generally consistent among taxa, with biochemistry (e.g., pigments), water content, and leaf structure as the primary drivers of absorption and scattering (Jacquemoud et al. 2009). Scaled up to the canopy-i.e., as viewed by a satellite- the interactions change due to both the structure and ecology of vegetation. Variations in leaf area and layering, leaf orientation distribution and clumping, multiple scattering, and canopy heterogeneity add complexity to the signal that varies based on gross vegetation structure (Jacquemoud et al. 2009). However, ecological differences among vegetation structural types may be as significant: In some cases, the structural variability itself may be important to characterizing ecological dimensions of biodiversity (Townsend et al. 2013) or may confound the detection of variables driving diversity (Knyazikhin et al. 2013). Most significantly, however, the interpretation of variability (diversity) in retrieved traits may differ among ecosystem types.

Because of vegetation structure, the algorithms to map components of biodiversity (e.g., functional traits; see Serbin and Townsend, Chap. 3) differ. For example, a key ecological trait to characterize ecosystems is leaf mass per area (LMA), which is frequently used as a basis to estimate photosynthetic capacity and is also representative of environmental or evolutionary trade-offs between leaf construction costs and carbon uptake, i.e., longevity (thick leaves or needles, high LMA) vs. fast growth (thin leaves, high leaf area, low LMA) (Díaz et al. 2016; Reich et al. 1992; Shipley et al. 2006; Wright et al. 2004).

Differences in algorithms among functional types are illustrated by the retrieval algorithms to predict LMA and nitrogen in grasslands vs. forests (Fig. 19.2), which exhibit considerable differences due to variations in bidirectional reflectance. Standardized partial least squares regression (PLSR) coefficients indicate the relative contribution of a wavelength to prediction of a trait, and PLSR is one among multiple methods for mapping traits from imaging spectroscopy (discussed in more detail in Serbin and Townsend, Chap. 3). PLSR coefficients are especially useful for diagnostic purposes because they can be interpreted with respect to known foliar features. Figure 19.1 illustrates the differences in PLSR retrievals between ecosystem types but also that combined equations are possible. Also, LMA and nitrogen are generally negatively correlated among ecosystems worldwide (Wright et al. 2004), and as a consequence their PLSR coefficients are inverse of each other at some wavelengths (e.g., the grassland and forest model at $1730 \mathrm{~nm}$ ).

The difference in structure among ecosystem types is driven in large part by several components of vegetation variation within a pixel. This has implications for both the derivation of biodiversity parameters and their interpretation. Leaf area index and canopy layering greatly influence the detection of vegetation characteristics. Elements of the canopy not directly exposed to the sun will be greatly reduced in significance for the calculation of any canopy characteristic. In forests, this means that a rich understory is often obscured, in contrast to a grassland in which many more components of the canopy are in the sunlit portion of the canopy exposed to a sensor. In addition to having technical consequences for the detection of functional or taxonomic diversity of a whole canopy, this also means that diversity metrics of 

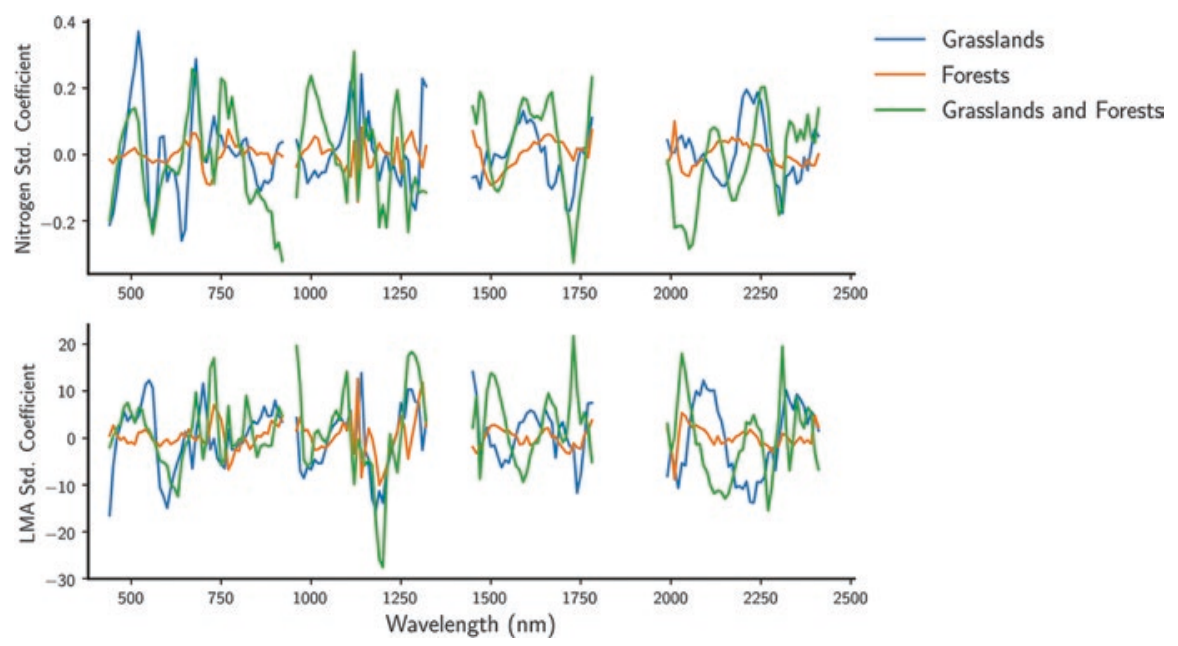

Fig. 19.1 Standardized partial least squares regression (PLSR) coefficients from three separate studies for predicting foliar nitrogen concentration and leaf mass per area (LMA). The standardized coefficients can be interpreted as the relative importance of each wavelength to retrieval of the trait. Differences in PLSR models between physiognomic types are generally related to canopy structure/physiognomic rather than leaf composition characteristics. The importance of different wavelengths varies due to both differences in absorption characteristics as a function of leaf structure and differences in canopy characteristics due to leaf shape, orientation, vertical layering, etc. Missing wavelengths are in spectral regions that are not used due to atmospheric absorption. (Grassland data from Wang et al. (2019), forest data from Singh et al. (2015), and grassland and forest data from Wang et al. (in revision). Model performance $\left(\mathrm{R}^{2}\right)$ for validation data: forest $\mathrm{LMA}=0.88, \% N=0.84 ;$ grassland $\mathrm{LMA}=0.83, \% N=0.57 ;$ together, $\mathrm{LMA}=0.78, \% N=0.55$ )

forests may not be fully informative compared to lower stature canopies. This can be mitigated in seasonal vegetation by imaging prior to leaf emergence or following canopy senescence, but this could be challenging given cloud cover and timing of 15-day repeat cycles. This forms a critical area for new research.

Canopy height and its variation are related confounding factors, as shadowing within canopies creates significant effects. Leaf physiognomy and shadowing add further complexity (e.g., consider the contrast between herbaceous vegetation with only vertically distributed graminoids and those with mixed grasses and broadleaf forbs). Likewise, broadleaf and conifer foliage in forests exhibit contrasting spectral characteristics at the leaf and canopy levels due to shading caused by angular distribution of needles. At a basic level, a structurally continuous canopy will exhibit lower diversity than a heterogeneous one; while this effect can be leveraged to characterize diversity, it is important to understand that the resulting spectral diversity is a consequence of the combination of biological, chemical, and physical characteristics of vegetation.

It is conceivable that an acceptable cross-ecotype model is possible for mapping some elements of biodiversity in different physiognomic vegetation types (see green lines in Fig. 19.1), but it is equally possible that better, or more precise, models will 
be achieved using stratification by a few biome types (grasslands/tundra, savannas, shrublands/forests). Indeed, this approach has been adopted for many global RS products, such as multiple MODIS variables (e.g., LAI, GPP). Much work is now required to develop practical, broadly applicable yet acceptably accurate and wellcharacterized retrievals for global application. More specific and computational methods, such as radiative transfer model inversion, may be used for local applications (Morsdorf et al., Chap. 4). The history of imaging spectroscopy has been of relatively small data collections from aircraft and from space with Hyperion (Pearlman et al. 2003), and as a result, investigators have not been greatly constrained by computation and have used algorithms that require a fair amount of manual intervention. The likely volume of data from a global spectrometer is so great that algorithms will have to run largely unattended and simple, robust approaches will be needed!

\subsection{Pixel Size}

Much of the extant literature on IS and ecology has been collected using airborne imagers flying at comparatively low altitudes, so that the pixels are quite small; 1-2 $\mathrm{m}^{2}$ is common (Asner et al. 2012; Kampe et al. 2010), and even data collected using NASA's research aircraft, the ER-2, flying at $>20,000 \mathrm{~m}$, are often $15 \mathrm{~m}^{2}$, smaller than the expected 30-45 $\mathrm{m}^{2}$ spaceborne pixels. Data on most of the dimensions of biodiversity can be tied to measurements or samples from not only a particular species but often an individual of that species. Most field sampling involves taxonomic identification followed by some sort of measurement or sampling process, increasingly tied to a geographic coordinate as well (Fig. 19.2).

By contrast, a $30 \mathrm{~m}$ pixel, 900 square meters, is not consistent with delineating a single organism or species in most cases. In fact, not only is there a scale mismatch between $30 \mathrm{~m}$ pixels and plants, but the magnitude of the mismatch depends on the ecosystem (see Gamon et al., Chap. 16). However conceptualized, the reality is that ecologists will have to cope with this range of mismatch and may only be able to inject intermediate scales at specific field sites, efforts which are likely to prove essential (Gamon et al., Chap. 16, Barnett et al. 2019). The range in size differences between plants and pixels is extraordinary. For example, to take one extreme, there is a factor of $10^{10}$ difference in size between a single phytoplankter and a $30 \mathrm{~m}$ pixel. A grassland represents an intermediate case, as a single grass plant (neglecting the fact that large swards of genetically identical individuals are known) is about $10^{-6}$ of a $30 \mathrm{~m}$ pixel, a million times smaller, while a large tree may cover a tenth or more of a $30 \mathrm{~m}$ pixel. There is thus not only a huge scale mismatch between plants and pixels, but the degree of mismatch may vary by $10^{9}$ between ecosystems.

The scale mismatch implies that the plant functional trait measurement from space characterizes a collection of organisms, a huge number for phytoplankton, and quite a large one for herbaceous plants, but possibly just a few individuals in a forest. The interpretation of the functional trait measurements will thus depend 


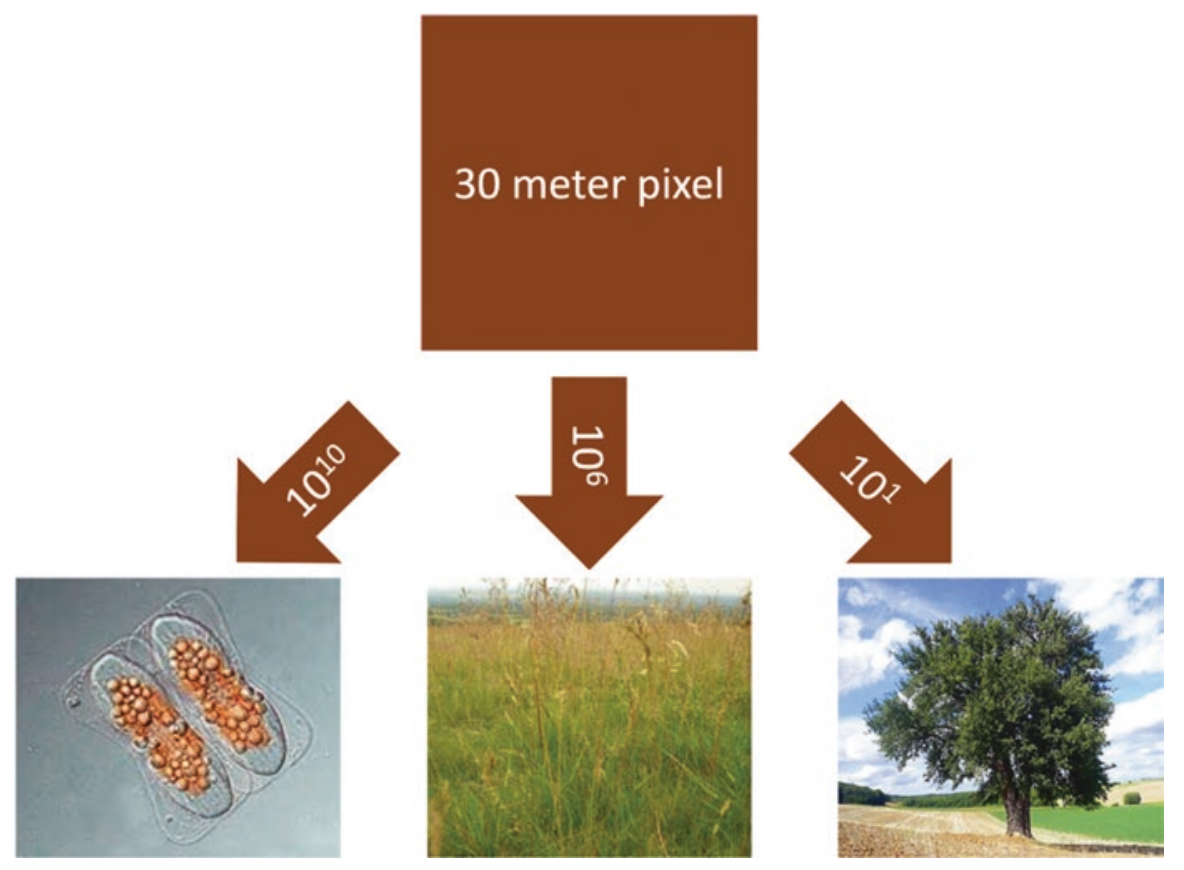

Fig. 19.2 The scale gap between organisms and the standard $30 \mathrm{~m}$ pixel ranges from $10^{10}$ to $10^{1}$, depending on whether phytoplankton or large canopy trees are being imaged. When spectroscopic data are applied to address ecological and phylogenetic questions, this scale gap will have to explicitly factor into the analysis

somewhat on the ecosystem type or the gradient of ecosystem types. If, for example, the diversity of plant functional traits estimated within a region (Asner et al. 2017) were to be used to look at some aspect of plant competition, assuming that plants with different functional traits are interacting competitively (as in many individualbased forest models), how would pixel-level diversity be used in such a framework? This requires research and validation to determine, since these models are usually built around data collected in association with taxonomic identification, or highly aggregated into generalized plant functional types. The pixel-level data could be intermediate between these current practices.

The scale mismatch also raises challenges with calibration and validation of plant functional trait estimates. In situ, these measurements are normally made on individual leaves or other tissue, or small composites of leaves, samples typically $1 / 10^{7}$ the size of a pixel. Within a pixel, distributed either horizontally or vertically within a canopy, trait values may vary dramatically (Schimel et al. 1991b; Serbin et al. 2014), and careful extrapolation is required to even compare with remote observations (Singh et al. 2015). This extrapolation itself has to be done differently, for example, in forests where vertically sun and shade leaves differ, compared to grasslands, where hundreds of species may partition the environment, varying in traits within this pixel and sampling representatively can be very challenging. 


\subsection{Phenology and Temporal Aggregation}

Functional traits and biodiversity are normally presented as stable characteristics of an ecosystem and are often mapped at broad scales (Butler et al. 2017; MorenoMartínez et al. 2018) as a snapshot and implemented within models as static data. When functional traits are observed in situ, they are typically based on species-level sampling, sometimes repeated over a phenological sequence, though most commonly near-peak biomass. By contrast, a satellite comes over at a fixed schedule and collects data when cloud and aerosol conditions permit. Data may be selected to capture maximum "greenness" or some other criterion (e.g., Kampe et al. 2010), or data may be collected multiple times each year.

In many ecosystems, the species visible to a sensor in space vary (Sherry et al. 2011) over the course of a growing season. What is the best way to characterize that system's functional diversity? The simple sum of traits over a seasonal cycle might double-count some species, while a peak greenness assessment might underestimate functional diversity and neglect functionally important species specialized to early or late season. A global imaging spectrometer with consistent repeat imaging will enable us to both (i) address the effects of vegetation phenology on the retrieval of foliar traits from imaging spectroscopy data and (ii) assess the phenological drivers of variation in functional diversity at unprecedented spatial and temporal scales. Existing studies have largely been conducted in periods of peak greenness, and neither the seasonal variability of vegetation traits nor the effects of seasonal variability on retrieval algorithms have been addressed. These will be needed for an instrument such as SBG, with a $\sim 15$-day return interval. Addressing this problem, like the spatial scaling problem, requires considering the measurement in the context of ecological theory as well as considering pragmatic reality.

\subsection{Conclusion}

The likely flight of a spaceborne imaging spectrometer, with global repeat coverage, represents a transformative moment in global ecology. For the first time, a global measurement will address not only the function of life on Earth, as do greenness and other older measures, but at least one dimension of the diversity of life on Earth. SBG, CHIME and precursor missions like HISUI and EnMAP will provide a unique view of the range of plant functions and will no doubt produce new insights about the range of function, the extent and distribution of functional diversity of plants, and new aspects of habitat for other trophic levels. In addition, global spectroscopy is likely to become available at a time when many other structural and functional dimensions of biodiversity and ecosystem function are also available, reviewed in Schimel, Schneider et al. (2019). The parallel emergence of new ecological observatories will provide a wealth of systematic ground data to aid in developing theory and practical algorithms (Barnett et al. 2019). A number of challenges need to be confronted in order to consistently integrate IS with ecological theory and with the 
other dimensions of biodiversity, and the upcoming years will be the critical time for ecologists to address these challenges.

Acknowledgments PT received support from NSF Dimensions of Biodiversity grant 1342778, NSF Macrosystems Biology and Early Neon Science grant 1638720, NASA/JPL contracts 1579654 and 1590148, and USDA McIntire-Stennis/Hatch awards WIS01809 and WIS01874. This research, carried out at the Jet Propulsion Laboratory, California Institute of Technology, was under a contract with the National Aeronautics and Space Administration, copyright 2019 California Institute of Technology. We also thank the NIMBioS working group on remote sensing of biodiversity.

\section{References}

Asner GP, Knapp DE, Boardman J, Green RO, Kennedy-Bowdoin T, Eastwood M, Martin RE, Anderson C, Field CB (2012/9) Carnegie airborne observatory-2: increasing science data dimensionality via high-fidelity multi-sensor fusion. Remote Sens Environ 124:454-465

Asner GP, Martin RE, Suhaili AB (2012) Sources of canopy chemical and spectral diversity in lowland Bornean Forest. Ecosystems 15(3):504-517

Asner GP, Martin RE, Knapp DE, Tupayachi R, Anderson CB, Sinca F, Vaughn NR, Llactayo W (2017) Airborne laser-guided imaging spectroscopy to map forest trait diversity and guide conservation. Science 355(6323):385-389

Barnett DT, Adler PB, Chemel BR, Duffy PA, Enquist BJ, Grace JB, Harrison S, Peet RK, Schimel DS, Stohlgren TJ, Vellend M (2019) The plant diversity sampling design for the National Ecological Observatory Network. Ecosphere 10(2):e02603. https://doi.org/10.1002/ecs2.2603

Bonan GB (2016) Ecological climatology: concepts and applications. 3rd edition. Cambridge University Press, Cambridge, p 692

Butler EE, Datta A, Flores-Moreno H, Chen M, Wythers KR, Fazayeli F, Banerjee A, Atkin OK, Kattge J, Amiaud B, Blonder B, Boenisch G, Bond-Lamberty B, Brown KA, Byun C, Campetella G, Cerabolini BEL, Cornelissen JHC, Craine JM, Craven D, de Vries FT, Díaz S, Domingues TF, Forey E, González-Melo A, Gross N, Han W, Hattingh WN, Hickler T, Jansen S, Kramer K, Kraft NJB, Kurokawa H, Laughlin DC, Meir P, Minden V, Niinemets Ü, Onoda Y, Peñuelas J, Read Q, Sack L, Schamp B, Soudzilovskaia NA, Spasojevic MJ, Sosinski E, Thornton PE, Valladares F, van Bodegom PM, Williams M, Wirth C, Reich PB (2017) Mapping local and global variability in plant trait distributions. Proc Natl Acad Sci U S A 114(51):E10937-E10946

Cavender-Bares J, Meireles J, Couture J, Kaproth M, Kingdon C, Singh A, Serbin S, Center A, Zuniga E, Pilz G, Townsend P (2016) Associations of leaf spectra with genetic and phylogenetic variation in oaks: prospects for remote detection of biodiversity. Remote Sens 8(3):221

Chapin FS 3rd (2003) Effects of plant traits on ecosystem and regional processes: a conceptual framework for predicting the consequences of global change. Ann Bot 91(4):455-463

Díaz S, Kattge J, Cornelissen JHC, Wright IJ, Lavorel S, Dray S, Reu B, Kleyer M, Wirth C, Prentice IC, Garnier E, Bönisch G, Westoby M, Poorter H, Reich PB, Moles AT, Dickie J, Gillison AN, Zanne AE, Chave J, Wright SJ, Sheremet'ev SN, Jactel H, Baraloto C, Cerabolini B, Pierce S, Shipley B, Kirkup D, Casanoves F, Joswig JS, Günther A, Falczuk V, Rüger N, Mahecha MD, Gorné LD (2016) The global spectrum of plant form and function. Nature 529(7585):167-171

Féret J-B, Asner GP (2014) Mapping tropical forest canopy diversity using high-fidelity imaging spectroscopy. Ecol Appl 24(6):1289-1296

Gholizadeh H, Gamon JA, Townsend PA, Zygielbaum AI, Helzer CJ, Hmimina GY, Yu R, Moore RM, Schweiger AK, Cavender-Bares J (2019) Detecting prairie biodiversity with airborne remote sensing. Remote Sens Environ 221:38-49 
Hobbs NT, Schimel DS, Owensby CE, Ojima DS (1991) Fire and grazing in the tallgrass prairie: contingent effects on nitrogen budgets. Ecology 72(4):1374-1382

Jacquemoud S, Verhoef W, Baret F, Bacour C, Zarco-Tejada PJ, Asner GP, François C, Ustin SL (2009) PROSPECT+ SAIL models: a review of use for vegetation characterization. Remote Sens Environ 113:S56-S66

Jetz W, Cavender-Bares J, Pavlick R, Schimel D, Davis FW, Asner GP, Guralnick R, Kattge J, Latimer AM, Moorcroft P, Schaepman ME, Schildhauer MP, Schneider FD, Schrodt F, Stahl U, Ustin SL (2016) Monitoring plant functional diversity from space. Nature Plants 2:16024

Kampe TU, Johnson BR, Kuester MA, Keller M (2010) NEON: the first continental-scale ecological observatory with airborne remote sensing of vegetation canopy biochemistry and structure. JARS 4(1):043510

Knyazikhin Y, Schull MA, Stenberg P, Mõttus M, Rautiainen M, Yang Y, Marshak A, Latorre Carmona P, Kaufmann RK, Lewis P, Disney MI, Vanderbilt V, Davis AB, Baret F, Jacquemoud S, Lyapustin A, Myneni RB (2013) Hyperspectral remote sensing of foliar nitrogen content. Proc Natl Acad Sci U S A 110(3):E185-E192

Melillo JM, Aber JD, Muratore JF (1982) Nitrogen and lignin control of hardwood leaf litter decomposition dynamics. Ecology 63(3):621-626

Moreno-Martínez Á, Camps-Valls G, Kattge J, Robinson N, Reichstein M, van Bodegom P, Kramer K, Cornelissen JHC, Reich P, Bahn M, Niinemets Ü, Peñuelas J, Craine JM, Cerabolini BEL, Minden V, Laughlin DC, Sack L, Allred B, Baraloto C, Byun C, Soudzilovskaia NA, Running SW (2018) A methodology to derive global maps of leaf traits using remote sensing and climate data. Remote Sens Environ 218:69-88

Mouroulis P, Van Gorp BE, White VE, Mumolo JM, Hebert D, Feldman M (2011) A compact, fast, wide-field imaging spectrometer system, in next-generation spectroscopic technologies IV. Int Soc Opt Photon 8032:80320U

National Academies of Sciences (2018) Engineering, and medicine: thriving on our changing planet: a decadal strategy for earth observation from space. The National Academies Press, Washington, DC

National Research Council (2007) Earth science and applications from space: national imperatives for the next decade and beyond. National Academies Press, Washington, DC

Ogawa K, Konno Y, Yamamoto S, Matsunaga T, Tachikawa T, Komoda M (2017) Observation planning algorithm of a Japanese space-borne sensor: hyperspectral imager SUIte (HISUI) onboard international Space Station (ISS) as platform, in sensors, systems, and next-generation satellites XXI. Int Soc Opt Photon 10423:104230R

Pearlman JS, Barry PS, Segal CC, Shepanski J, Beiso D, Carman SL (2003) Hyperion, a spacebased imaging spectrometer. IEEE Trans Geosci Remote Sens 41(6):1160-1173

Poorter H, Niinemets U, Poorter L, Wright IJ, Villar R (2009) Causes and consequences of variation in leaf mass per area (LMA): a meta-analysis. New Phytologist 182:565-588

Rast M, Ananasso C, Bach H, Dor EB, Chabrillat S, Colombo R, Bello UD, Feret J-B, Giardino C, Green RO, Guanter L, Marsh S, Mieke J, Ong C, Rum G, Schaepman M, Schlerf M, Skidmore AK, Strobi P (2019) Copernicus hyperspectral imaging mission for the environment (CHIME) mission requirements document. 2019. European Space Agency. ESA-EOPSM-CHIMMRD-3216. http://esamultimedia.esa.int/docs/EarthObservation/Copernicus_CHIME_MRD_ v2.1_Issued20190723.pdf

Reich PB, Walters MB, Ellsworth DS (1992) Leaf life-span in relation to leaf, plant, and stand characteristics among diverse ecosystems. Ecol Monogr 62(3):365-392

Saatchi S, Mascaro J, Xu L, Keller M, Yang Y, Duffy P, Espírito-Santo F, Baccini A, Chambers J, Schimel D (2015) Seeing the forest beyond the trees. Glob Ecol Biogeogr 24(5):606-610

Schimel DS, Kittel TGF, Knapp AK, Seastedt TR, Parton WJ, Brown VB (1991a) Physiological interactions along resource gradients in a tallgrass prairie. Ecology 72(2):672-684

Schimel DS, Kittel TGF, Parton WJ (1991b) Terrestrial biogeochemical cycles: global interactions with the atmosphere and hydrology. Tellus A 43(4):188-203

Schimel DS, Asner GP, Moorcroft P (2013) Observing changing ecological diversity in the Anthropocene. Front Ecol Environ 11(3):129-137 
Schimel D, Schneider F, JPL Carbon and Ecosystem Participants (2019) Flux towers in the sky: global ecology from space. New Phytologist (2019) 224:570-584. https://doi.org/10.1111/ nph. 15934

Schneider FD, Morsdorf F, Schmid B, Petchey OL, Hueni A, Schimel DS, Schaepman ME (2017) Mapping functional diversity from remotely sensed morphological and physiological forest traits. Nat Commun 8(1):1441

Serbin SP, Singh A, McNeil BE, Kingdon CC, Townsend PA (2014) Spectroscopic determination of leaf morphological and biochemical traits for northern temperate and boreal tree species. Ecol Appl 24(7):1651-1669

Sherry RA, Zhou X, Gu S, Arnone JA, Johnson DW, Schimel DS, Verburg PSJ, Wallace LL, Luo $Y$ (2011) Changes in duration of reproductive phases and lagged phenological response to experimental climate warming. Plant Ecol Divers 4(1):23-35

Shipley B, Lechowicz MJ, Wright I, Reich PB (2006) Fundamental trade-offs generating the worldwide leaf economics spectrum. Ecology 87(3):535-541

Singh A, Serbin SP, McNeil BE, Kingdon CC, Townsend PA (2015) Imaging spectroscopy algorithms for mapping canopy foliar chemical and morphological traits and their uncertainties. https://doi.org/10.1890/14-2098.1

Thompson DR, Boardman JW, Eastwood ML, Green RO (2017) A large airborne survey of Earth's visible-infrared spectral dimensionality. Opt Express 25(8):9186-9195

Townsend PA, Serbin SP, Kruger EL, Gamon JA (2013) Disentangling the contribution of biological and physical properties of leaves and canopies in imaging spectroscopy data. Proc Natl Acad Sci U S A 110(12):E1074

Ustin SL, Wessman CA, Curtis B, Kasischke E, Way J, Vanderbilt VC (1991) Opportunities for using the EOS imaging spectrometers and synthetic aperture radar in ecological models. Ecology 72(6): 1934-1945

Verheijen LM, Aerts R, Brovkin V, Cavender-Bares J, Cornelissen JHC, Kattge J, van Bodegom PM (2015) Inclusion of ecologically based trait variation in plant functional types reduces the projected land carbon sink in an earth system model. Glob Chang Biol 21(8):3074-3086

Wang Z, Townsend PA, Schweiger AK, Couture JJ, Singh A, Hobbie SE, Cavender-Bares J (2019) Mapping foliar functional traits and their uncertainties across three years in a grassland experiment. Remote Sens Environ 221:405-416

Wang Z, Chlus A, Geygan R, Singh A, Couture JJ, Kruger EL, Townsend PA In prep. A database of foliar functional trait maps across NEON domains in eastern U.S. Ecology

Wessman CA, Aber JD, Peterson DL, Melillo JM (1988) Remote sensing of canopy chemistry and nitrogen cycling in temperate forest ecosystems. Nature 335(6186):154-156

Wright IJ, Reich PB, Westoby M, Ackerly DD, Baruch Z, Bongers F, Cavender-Bares J, Chapin T, Cornelissen JHC, Diemer M, Flexas J, Garnier E, Groom PK, Gulias J, Hikosaka K, Lamont BB, Lee T, Lee W, Lusk C, Midgley JJ, Navas M-L, Niinemets U, Oleksyn J, Osada N, Poorter H, Poot P, Prior L, Pyankov VI, Roumet C, Thomas SC, Tjoelker MG, Veneklaas EJ, Villar R (2004) The worldwide leaf economics spectrum. Nature 428(6985):821-827

Open Access This chapter is licensed under the terms of the Creative Commons Attribution 4.0 International License (http://creativecommons.org/licenses/by/4.0/), which permits use, sharing, adaptation, distribution and reproduction in any medium or format, as long as you give appropriate credit to the original author(s) and the source, provide a link to the Creative Commons license and indicate if changes were made.

The images or other third party material in this chapter are included in the chapter's Creative Commons license, unless indicated otherwise in a credit line to the material. If material is not included in the chapter's Creative Commons license and your intended use is not permitted by statutory regulation or exceeds the permitted use, you will need to obtain permission directly from the copyright holder.

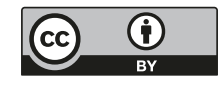

